\title{
Printing "Smart" Inks of Redox-Responsive Organometallic Polymers on Microelectrode Arrays for Molecular Sensing
}

\author{
Marco Cirelli, ${ }^{\dagger, \ddagger \odot ~ J i n m e n g ~ H a o, ~}{ }^{\dagger}$ Teunis C. Bor, ${ }^{\ddagger}$ Joost Duvigneau, ${ }^{\dagger}{ }^{\dagger}$ Niels Benson, ${ }^{\S}$
} Remko Akkerman, Mark A. Hempenius, ${ }^{\dagger}$ and G. Julius Vancso ${ }^{*}{ }^{\dagger}{ }^{\circ}$

\begin{abstract}
${ }^{\dagger}$ Materials Science and Technology of Polymers, MESA+ Institute for Nanotechnology, and ${ }^{\ddagger}$ Production Technology, Faculty of Engineering Technology, University of Twente, P.O. Box 217, 7500 AE Enschede, The Netherlands

${ }^{\S}$ Institute of Technology for Nanostructures, Faculty of Engineering, University of Duisburg-Essen (UDE), Bismarckstr. 81, D-47057 Duisburg, Germany
\end{abstract}

\section{Supporting Information}

ABSTRACT: Printing arrays of responsive spots for multiplexed sensing with electrochemical readout requires new molecules and precise, high-throughput deposition of active compounds on microelectrodes with spatial control. We have designed and developed new redox-responsive polymers, featuring a poly(ferrocenylsilane) (PFS) backbone and side groups with disulfide units, which allow an efficient and stable bonding to Au substrates, using sulfur-gold coupling chemistry in a "grafting-to" approach. The polymer molecules can be employed for area selective molecular sensing following their deposition by high-precision inkjet printing. The new PFS derivatives, which serve as "molecular inks", were characterized by ${ }^{1} \mathrm{H} \mathrm{NMR},{ }^{13} \mathrm{C} \mathrm{NMR}$, and FTIR spectroscopies and by gel permeation chromatography. The viscosity and surface tension of the inks were assessed by rheology and pendant drop contact angle measurements, respectively. Commercial microelectrode arrays were modified with the new PFS ink by using

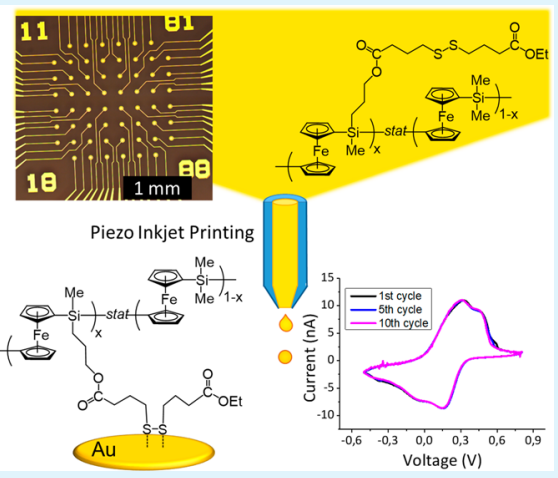
inkjet printing in the "drop-on-demand" mode. FTIR spectroscopy, AFM, and EDX-SEM confirmed a successful, spatially localized PFS modification of the individual electrodes within the sensing cells of the microelectrode arrays. The potential application of these devices to act as an electrochemical sensor array was demonstrated with a model analyte, ascorbic acid, by using cyclic voltammetry and amperometric measurements.

KEYWORDS: inkjet printing, electrochemical sensors, poly(ferrocenylsilane) (PFS), microelectrode array (MEA) chip, drop-on-demand (DoD)

\section{INTRODUCTION}

Microelectrode arrays (MEAs) allow one to perform multiplexed parallel analysis of complex mixtures of redox-active analytes with selective and specific sensing of the individual constituents in the microelectrode cells that make up the array. ${ }^{1-10}$ For a successful implementation of such devices one could consider selective printing of specific sensing molecular inks into the individual microelectrode cells (MEs) that can exhibit a different composition from "pixel" to "pixel" within the array. ${ }^{6-10}$ The recognition inks should adhere to the ME surface and provide analyte selective signals. Printing using multiple reservoirs would be needed to render each electrochemical microcell working as a specific sensing element.

Toward achieving this objective, we describe in this contribution the first necessary steps including (a) the development of a novel redox stimulus responsive molecular ink and (b) the construction of single ME sensing "pixels" using one printing reservoir and a single nozzle. By doing so, we provide elements for designing devices such as "aiming" the ink to accurately hit the microelectrode with high printing accuracy. We describe how printing accuracy can be evaluated.
We then test the ME device concept in a model sensing process.

Stimulus responsive (or "smart") polymers have been in the focus of recent interest due to their ability to be used in functional, integrated material constructs for wetting and friction control, sensing, monitoring, and steering processes, in mechanical actuation as self-healing biomedical platforms, and in molecular delivery. ${ }^{11-16}$ Among the many possible stimuli utilized in conjunction with polymers, electrochemical (redox) control has received relatively little attention when compared to temperature, $\mathrm{pH}$, light, and chemical stimuli. ${ }^{17-21}$ One of the reasons for the employment of the "classical" stimuli is that the range of synthetic polymers, which exhibit a reversible redox response, is rather limited. ${ }^{17,19-21}$

The emerging class of redox-responsive organometallic poly(ferrocenylsilane)s (PFSs), which feature alternating ferrocene units and substituted bridging $\mathrm{Si}$ in the main chain,

Received: July 8, 2019

Accepted: September 16, 2019

Published: September 16, 2019 
have shown a great potential to fabricate redox-sensitive molecular sensing platforms. ${ }^{21-24}$ In PFSs the silane units can be employed in substitution chemistry, yielding a broad range of functional macromolecules. The variation of side-group structure allows one to tune the physical and chemical properties of PFS, while the ferrocene units remain responsible for preserving the redox activity. ${ }^{22-26}$ The stimulus-responsive behavior implies that changes of the redox environmental conditions trigger changes of the oxidation state of the iron atom in the ferrocene group. We note that redox chemistry of PFS, including chemical and electrochemical redox transitions, has been subject of several studies. ${ }^{18,26-29}$ Corresponding papers discuss intra- and interchain electron transfer during electrochemical oxidation/reduction ${ }^{30,31}$ as well as the effect of chemical oxidizing and reducing agents ${ }^{23}$ and redox behavior of PFS attached to the surface of various substrates. ${ }^{20,21}$ PFSdecorated electrodes have been used for electrochemical sensing of ascorbic acid, ${ }^{20,32-34}$ hydrogen peroxide, ${ }^{34}$ glucose, ${ }^{35,36}$ and inorganic ions ${ }^{37}$ and/or to enhance detection sensitivity ${ }^{18,21}$ and photoconductivity. ${ }^{38}$

MEAs have been successfully utilized in many areas in biomedical applications ${ }^{1,3-5}$ as well as in environmental sensing 2,39,40 $^{\text {and food quality monitoring. }}{ }^{9,40}$ The reason for this interest is that MEAs enable the stimulation and recording of electrical signals of multiple MEs with low background charging and high current density. This is related to the efficient mass transport of the redox-active species to and from the micro-sized electrode surface (i.e., the electrode diameter is $<100 \mu \mathrm{m})$ and the bulk solution. ${ }^{6,10,41}$

One of the many challenges in the development of multiplexed MEA sensors is to individually and independently immobilize functional coatings onto the electrode surface of each of the MEs with a high quality of spatial control. ${ }^{7,9,42,43}$ Benefits of precise deposition of responsive functional coatings are expected to further boost the use of MEAs, for example, by fabrication of MEAs on soft materials or functionalization of MEAs improving their performance and biocompatibility. ${ }^{44}$ This would allow in situ multiplex sensing, cell patterning, and delivery applications. ${ }^{2,4,9,39,40,43}$ Two main strategies can be used to chemically immobilize sensing macromolecules on different electrode surfaces encompassing the "grafting from" $16,45-47$ or the "grafting to"16,48 approaches. In this study, we decorated bare gold ME surfaces via the "grafting to" approach employing the well-known strong and stable sulfurgold binding chemistry. ${ }^{49,50}$

Various sulfur-containing PFS macromolecules have been prepared and reported previously. For example, end-capping of living PFS chains with ethylene sulfide provided access to thiol end-functionalized PFSs. ${ }^{51}$ Postpolymerization modification using thiol-ene chemistry proved to be another highly versatile approach to obtain sulfur-functionalized PFSs. ${ }^{52}$ In this study, first a PFS random copolymer possessing a tailored amount of reactive halopropyl side groups was synthesized via platinum-catalyzed ring-opening polymerization of siliconbridged ferrocenophanes. ${ }^{53,54}$ Then, disulfide moieties were attached to the haloalkyl groups by nucleophilic substitution to afford disulfide-functionalized PFSs with a well-controlled composition capable to covalently graft to gold surfaces, as is shown in Figure 1.

Molecular surface immobilization of PFS films on the electrodes investigated here was already realized via the grafting to approach, layer-by-layer (LbL), ${ }^{34,55}$ drop-casting, ${ }^{32}$ dip-coating, ${ }^{51}$ spin-coating, ${ }^{56}$ and electrografting ${ }^{33}$ deposition

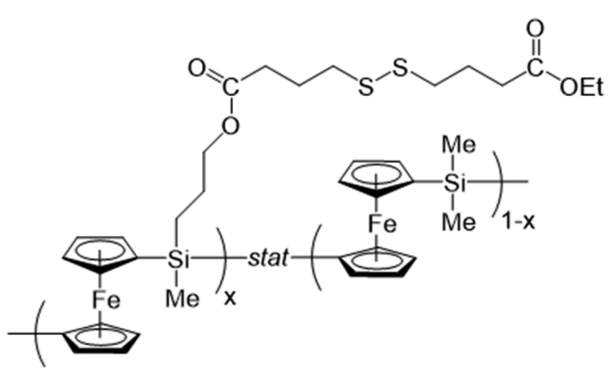

Figure 1. Structure of the disulfide-functionalized poly(ferrocenylsilane) copolymer used in this study.

techniques. In previous work of Vancso et al., the immobilization of PFS derivatives in a LbL fashion on MEAs was achieved by physical immobilization (i.e., electrostatic interactions) and used to fabricate a redox-responsive multilayer platform for local controlled release of multiple molecular payloads from the surfaces. ${ }^{55}$ In comparison to these techniques, inkjet printing technology is a very promising, reliable and convenient way for patterning by deposition to individually decorate the MEA cells. The advantages of this technique include contact-free deposition on the electrode substrates (minimizing contaminations or alterations), no need of masks, versatile applicability, and targeted delivery. ${ }^{57-61}$ The ink can be water- or organic-solvent-based, and good repeatability and spatial accuracy in the deposition process have been achieved. ${ }^{62,63}$ Inkjet printing can be performed in continuous inkjet (C-IJ) or in drop-on-demand (DoD-IJ) modes. In C-IJ, the ink solution is pumped through a nozzle to form a liquid jet. This mode is mainly used in high-speed graphical applications due to the high throughput of the production. In the DoD-IJ mode the droplet is formed by an acoustic pulse, generated by a piezoelectric or thermal trigger, and is printed from a reservoir through a nozzle with high placement accuracy. Employing the DoD mode minimizes the amount of ink used for the deposition (few tens of picoliters) and thus reduces ink waste and minimizes the consumption of the functional compound.

Therefore, following a thorough characterization of the here described novel PFS-based ink, we performed printability tests and evaluated the accuracy, chemical composition, and topological and morphological features of the PFS printed patterns. The PFS-modified MEAs were then tested as an ascorbic acid sensor in a case study. To this end, the stability and the electrochemical properties of the tethered PFS polymer films via cyclic voltammetry and chronoamperometry experiments were assessed.

\section{EXPERIMENTAL SECTION}

Synthesis and Characterization of Disulfide-Functionalized Poly(ferrocenylsilane)s, PFS 5. 4,4'-Dithiodibutyric Acid Monoethyl Ester. 4,4'-Dithiodibutyric acid (DTDB) was alkylated following a published procedure. ${ }^{64} \mathrm{~A}$ suspension of powdered potassium hydroxide $85 \%(1.33 \mathrm{~g}, 20 \mathrm{mmol})$ in DMSO $(13 \mathrm{~mL})$ was stirred vigorously for $30 \mathrm{~min}$ at room temperature. A solution of DTDB $(2.384 \mathrm{~g}, 9.5 \mathrm{mmol})$ was added in DMSO $(10 \mathrm{~mL})$, and the mixture was stirred for $15 \mathrm{~min}$. After cooling in an ice-water bath, a solution of iodoethane $(2.23 \mathrm{~g}, 14.3 \mathrm{mmol})$ in DMSO $(20 \mathrm{~mL})$ was added by using a dropping funnel. Stirring was continued for $2 \mathrm{~h}$ at room temperature, followed by the addition of ice-water $(150 \mathrm{~mL})$. The $\mathrm{pH}$ value of the mixture was adjusted to $\mathrm{pH} \mathrm{3-4}$ with dilute hydrochloric acid. The resulting solution was extracted three times with ethyl acetate $(3 \times 15 \mathrm{~mL})$, and the organic layer was washed 
three times with saturated aqueous sodium chloride $(3 \times 15 \mathrm{~mL})$. The solution was dried over anhydrous sodium sulfate and concentrated under reduced pressure. Purification was performed by column chromatography using $n$-hexane/acetone (1:1 vol:vol) as eluent to obtain $1.27 \mathrm{~g}(4.77 \mathrm{mmol})$ of product. Yield: $50.2 \%$.

${ }^{1} \mathrm{H}$ NMR $\left(400 \mathrm{MHz}, \mathrm{CDCl}_{3}\right) \delta: 1.25\left(\mathrm{CH}_{3}, \mathrm{t}, 3 \mathrm{H}\right) ; 2.015(\mathrm{O}=$ $\left.\mathrm{CCH}_{2} \mathrm{CH}_{2}, \mathrm{~m}, 4 \mathrm{H}\right) ; 2.42\left(\mathrm{O}=\mathrm{CCH}_{2}, \mathrm{t}, 2 \mathrm{H}\right) ; 2.49\left(\mathrm{O}=\mathrm{CCH}_{2}, \mathrm{t}\right.$, $2 \mathrm{H}) ; 2.715\left(\mathrm{CH}_{2} \mathrm{SSCH}_{2}, \mathrm{~m}, 4 \mathrm{H}\right) ; 4.125\left(\mathrm{CH}_{2} \mathrm{CH}_{3}, \mathrm{~m}, 2 \mathrm{H}\right) .{ }^{13} \mathrm{C}$ NMR $\left(100 \mathrm{MHz}, \mathrm{CDCl}_{3}\right) \delta: 14.22\left(\mathrm{CH}_{3}\right) ; 23.91\left(\mathrm{O}=\mathrm{CCH}_{2} \mathrm{CH}_{2}\right)$; $24.22\left(\mathrm{O}=\mathrm{CCH}_{2} \mathrm{CH}_{2}\right) ; 32.36\left(\mathrm{O}=\mathrm{CCH}_{2}\right) ; 32.66\left(\mathrm{O}=\mathrm{CCH}_{2}\right)$; $37.59\left(\mathrm{CH}_{2} \mathrm{SSCH}_{2}\right) ; 37.81\left(\mathrm{CH}_{2} \mathrm{SSCH}_{2}\right) ; 60.55\left(\mathrm{CH}_{2} \mathrm{CH}_{3}\right) ; 173.14$ $(\mathrm{C}=\mathrm{O}) ; 178.53(\mathrm{C}=\mathrm{O})$. IR $\left(4000-500 \mathrm{~cm}^{-1}\right.$, ATR-FTIR Bruker ALPHA): $3400-2800 \mathrm{~cm}^{-1}(\mathrm{O}-\mathrm{H}$ stretching vibration, $\nu \mathrm{O}-\mathrm{H})$, acid), 1728 and $1704 \mathrm{~cm}^{-1}(\mathrm{C}=\mathrm{O}$ stretching vibrations, $\nu \mathrm{C}=\mathrm{O})$, $510 \mathrm{~cm}^{-1}$ (S-S stretching vibration of disulfide group, $\nu \mathrm{S}-\mathrm{S}$ ).

Chloropropyl-Functionalized PFS 3. In a glovebox filled with prepurified $\mathrm{N}_{2}$, [1] dimethylsilaferrocenophane $1\left(1.40 \mathrm{~g}, 5.78 \times 10^{-3}\right.$ $\mathrm{mol}$ ) and [1](3-chloropropyl)methylsilaferrocenophane $2(93 \mathrm{mg}$, $\left.3.05 \times 10^{-4} \mathrm{~mol}, 5 \mathrm{~mol} \%\right)$ were dissolved in dry THF $(20 \mathrm{~mL})$ in a $50 \mathrm{~mL}$ one-necked round-bottom flask. A small grain of hexachloroplatinic acid $(5 \mathrm{mg})$ was added under stirring according to a wellestablished procedure. $^{53,54}$ Stirring was continued for $36 \mathrm{~h}$. The solution was then diluted by adding THF $(10 \mathrm{~mL})$, and the polymer was precipitated in $\mathrm{MeOH}(200 \mathrm{~mL})$. This mixture was stirred for $1 \mathrm{~h}$ to coagulate the polymer. After the polymer was isolated, it was precipitated again in $\mathrm{MeOH}$, dried in a flow of $\mathrm{N}_{2}$, and further dried under vacuum ( $6 \mathrm{mbar}, 24 \mathrm{~h}$, followed by $\left.1 \times 10^{-3} \mathrm{mbar}, 24 \mathrm{~h}\right)$. Yield: $1.40 \mathrm{~g}$.

${ }^{1} \mathrm{H}$ NMR (400 MHz, toluene- $\left.d_{8}\right) \delta: 0.53\left(\mathrm{SiCH}_{3}, \mathrm{~s}, 6 \mathrm{H}\right) ; 0.98(\mathrm{Si}-$ $\left.\mathrm{CH}_{2}, \mathrm{~m}, 0.16 \mathrm{H}\right) ; 1.77\left(\mathrm{CH}_{2}, \mathrm{~m}, 0.16 \mathrm{H}\right) ; 3.24\left(\mathrm{CH}_{2} \mathrm{Cl}, \mathrm{t}, 0.16 \mathrm{H}\right) ; 4.06$ $+4.24(\mathrm{Cp}, \mathrm{m}, 8 \mathrm{H})$, as shown in Figure S1. ${ }^{13} \mathrm{C}$ NMR $(100 \mathrm{MHz}$, toluene- $\left.d_{8}\right) \delta:-2.97 \quad\left(\mathrm{CH}_{3} \mathrm{SiCH}_{2}\right) ;-0.54\left(\mathrm{CH}_{3} \mathrm{SiCH}_{3}\right) ; 14.38$ $\left(\mathrm{SiCH}_{2}\right) ; 28.34\left(\mathrm{CH}_{2}\right) ; 48.06\left(\mathrm{CH}_{2} \mathrm{Cl}\right) ; 71.75+73.62(\mathrm{Cp})$, as shown in Figure S2. FTIR $\left(4000-500 \mathrm{~cm}^{-1}\right): 1380,1361$, and 1248 $\mathrm{cm}^{-1}\left(\mathrm{SiCH}_{3}\right.$ deformation vibrations); 1450 and $1350 \mathrm{~cm}^{-1}(\mathrm{C}-\mathrm{H}$ bending vibrations alkanes); 1182 and $1165 \mathrm{~cm}^{-1}$ (asymmetric ring in-plane $\mathrm{C}-\mathrm{H}$ vibrations for ferrocene rings); $1037 \mathrm{~cm}^{-1}$ (asymmetric ring out-of-plane $\mathrm{C}-\mathrm{H}$ vibrations for ferrocene rings), $800-600 \mathrm{~cm}^{-1}$ (C-Cl stretching vibrations, $\nu \mathrm{C}-\mathrm{Cl}$ ). GPC in THF: $M_{\mathrm{n}}=236702 \mathrm{~g} /$ $\mathrm{mol}, M_{\mathrm{w}}=383590 \mathrm{~g} / \mathrm{mol}, M_{\mathrm{w}} / M_{\mathrm{n}}=1.62$.

lodopropyl-Functionalized PFS 4. PFS $3(1.30 \mathrm{~g})$ was dissolved in THF $(40 \mathrm{~mL})$ and dicyclohexano-18-crown-6 $(1.0 \mathrm{~g}, 2.7 \mathrm{mmol}), \mathrm{KI}$ $(1.0 \mathrm{~g}, 6.0 \mathrm{mmol})$, and 1-iodopropane $(3 \mathrm{~mL}, 31 \mathrm{mmol})$ were added. The reaction mixture was stirred at $40{ }^{\circ} \mathrm{C}$ for 2 weeks. Following a week, some iodopropane $(2 \mathrm{~mL})$ was added. The polymer was precipitated twice in $\mathrm{MeOH}(200 \mathrm{~mL})$, dried in a flow of $\mathrm{N}_{2}$, and further dried under vacuum $\left(6 \mathrm{mbar}, 24 \mathrm{~h}\right.$, followed by $1 \times 10^{-3}$ mbar, $24 \mathrm{~h})$. Yield: $1.35 \mathrm{~g}$.

${ }^{1} \mathrm{H}$ NMR (400 MHz, toluene- $\left.d_{8}\right) \delta: 0.53\left(\mathrm{SiCH}_{3}, \mathrm{~s}, 6 \mathrm{H}\right) ; 0.95(\mathrm{Si}-$ $\left.\mathrm{CH}_{2}, \mathrm{~m}, 0.16 \mathrm{H}\right) ; 1.79\left(\mathrm{CH}_{2}, \mathrm{~m}, 0.16 \mathrm{H}\right) ; 2.88\left(\mathrm{CH}_{2} \mathrm{I}, \mathrm{t}, 0.16 \mathrm{H}\right) ; 4.06$ $+4.24(\mathrm{Cp}, \mathrm{m}, 8 \mathrm{H})$, as shown in Figure S3. ${ }^{13} \mathrm{C}$ NMR $(100 \mathrm{MHz}$, toluene- $\left.d_{8}\right) \delta:-2.94 \quad\left(\mathrm{CH}_{3} \mathrm{SiCH}_{2}\right) ;-0.55 \quad\left(\mathrm{CH}_{3} \mathrm{SiCH}_{3}\right) ; 11.59$ $\left(\mathrm{SiCH}_{2}\right) ; 18.55\left(\mathrm{CH}_{2}\right) ; 29.33\left(\mathrm{CH}_{2} \mathrm{I}\right) ; 71.74+73.61(\mathrm{Cp})$, as shown in Figure S4. FTIR (Bruker ALPHA, $4000-500 \mathrm{~cm}^{-1}$ ): 1380, 1361 , and $1248 \mathrm{~cm}^{-1}$ ( $\mathrm{SiCH}_{3}$ deformation vibrations); 1450 and 1350 $\mathrm{cm}^{-1}$ (C-H bending vibrations alkanes); 1182 and $1165 \mathrm{~cm}^{-1}$ (asymmetric ring in-plane $\mathrm{C}-\mathrm{H}$ vibrations for ferrocene rings); $1037 \mathrm{~cm}^{-1}$ (asymmetric ring out-of-plane $\mathrm{C}-\mathrm{H}$ vibrations for ferrocene rings). GPC in THF: $M_{\mathrm{n}}=126718 \mathrm{~g} / \mathrm{mol}, M_{\mathrm{w}}=235494$ $\mathrm{g} / \mathrm{mol}$, and $M_{\mathrm{w}} / M_{\mathrm{n}}=1.86$.

Disulfide-Functionalized PFS 5. 4,4-Dithiodibutyric acid monoethyl esther $(0.352 \mathrm{~g}, 1.32 \mathrm{mmol})$, dicyclohexano-18-crown-6 (0.50 g, $1.34 \mathrm{mmol})$, and $\mathrm{K}_{2} \mathrm{CO}_{3}(0.174 \mathrm{~g}, 1.26 \mathrm{mmol})$ were dissolved in DMF $(10 \mathrm{~mL})$ in a $25 \mathrm{~mL}$ round-bottom flask under $\mathrm{N}_{2}$. After stirring for $2 \mathrm{~h}$, the solution was taken up in a syringe and added to a solution of PFS $4(1.129 \mathrm{~g})$ in THF $(20 \mathrm{~mL})$, which was also kept under a nitrogen atmosphere. The flask containing the 4,4-dithiodibutyric acid monoethyl esther was rinsed twice with DMF $(2 \mathrm{~mL})$, which was also transferred by syringe to the PFS solution. The reaction mixture was stirred for 1 week at $20{ }^{\circ} \mathrm{C}$ and then added dropwise to methanol
$(200 \mathrm{~mL})$ to precipitate the polymer. The polymer was precipitated again from THF $(20 \mathrm{~mL})$ into $\mathrm{MeOH}(200 \mathrm{~mL})$, dried in a flow of $\mathrm{N}_{2}$, and further dried under vacuum $(6 \mathrm{mbar}, 24 \mathrm{~h}$, followed by $1 \times$ $10^{-3}$ mbar, $24 \mathrm{~h}$ ). Yield: $1.13 \mathrm{~g}$.

${ }^{1} \mathrm{H}$ NMR (400 MHz, toluene- $\left.d_{8}\right) \delta: 0.53\left(\mathrm{SiCH}_{3}, \mathrm{~s}, 6 \mathrm{H}\right) ; 0.95(\mathrm{Si}-$ $\left.\mathrm{CH}_{2}, \mathrm{~m}, 0.16 \mathrm{H}\right) ; 1.00\left(\mathrm{CH}_{2} \mathrm{CH}_{3}, \mathrm{t}\right) ; 1.77\left(\mathrm{SiCH}_{2} \mathrm{CH}_{2}, \mathrm{~m}, 0.16 \mathrm{H}\right)$; $1.87\left(\mathrm{O}=\mathrm{CCH}_{2} \mathrm{CH}_{2}, \mathrm{~m}\right) ; 1.92\left(\mathrm{O}=\mathrm{CCH}_{2} \mathrm{CH}_{2}, \mathrm{~m}\right) ; 2.14(\mathrm{O}=$ $\left.\mathrm{CCH}_{2}, \mathrm{~m}, 0.16 \mathrm{H}\right) ; 2.23\left(\mathrm{O}=\mathrm{CCH}_{2}, \mathrm{~m}, 0.16 \mathrm{H}\right) ; 2.45\left(\mathrm{CH}_{2} \mathrm{SSCH}_{2}\right.$, $\mathrm{m}, 0.24 \mathrm{H}) ; 4.06+4.24(\mathrm{Cp}, \mathrm{m}, 8 \mathrm{H})$, as shown in Figure $\mathrm{S} 5 .{ }^{13} \mathrm{C}$ NMR $\left(100 \mathrm{MHz}\right.$, toluene- $\left.d_{8}\right) \quad \delta:-2.97\left(\mathrm{CH}_{3} \mathrm{SiCH}_{2}\right) ;-0.56$ $\left(\mathrm{CH}_{3} \mathrm{SiCH}_{3}\right) ; 12.89\left(\mathrm{SiCH}_{2}\right) ; 14.35\left(\mathrm{CH}_{2} \mathrm{CH}_{3}\right) ; 24.57(\mathrm{O}=$ $\left.\mathrm{CCH}_{2} \mathrm{CH}_{2}\right) ; 24.64\left(\mathrm{O}=\mathrm{CCH}_{2} \mathrm{CH}_{2}\right) ; 32.56\left(\mathrm{O}=\mathrm{CCH}_{2}\right) ; 32.65$ $\left(\mathrm{O}=\mathrm{CCH}_{2}\right) ; 37.94\left(\mathrm{CH}_{2} \mathrm{SSCH}_{2}\right) ; 60.08\left(\mathrm{CH}_{2} \mathrm{CH}_{3}\right) ; 71.73+73.60$ $(\mathrm{Cp}) ; 172.04(\mathrm{C}=\mathrm{O}) ; 172.24(\mathrm{C}=\mathrm{O})$, as shown in Figure S6. FTIR $\left(4000-500 \mathrm{~cm}^{-1}\right): 1750$ and $1735 \mathrm{~cm}^{-1}(\mathrm{C}=\mathrm{O}$ stretching vibrations of ester groups, $\nu \mathrm{C}=\mathrm{O}) ; 1380,1361$, and $1248 \mathrm{~cm}^{-1}\left(\mathrm{SiCH}_{3}\right.$ deformation vibrations); 1450 and $1350 \mathrm{~cm}^{-1}(\mathrm{C}-\mathrm{H}$ bending vibrations alkanes); 1182 and $1165 \mathrm{~cm}^{-1}$ (asymmetric ring in-plane $\mathrm{C}-\mathrm{H}$ vibrations for ferrocene rings); $1037 \mathrm{~cm}^{-1}$ (asymmetric ring out-of-plane C-H vibrations for ferrocene rings). GPC in THF: $M_{\mathrm{n}}=$ $138498 \mathrm{~g} / \mathrm{mol}, M_{\mathrm{w}}=278794 \mathrm{~g} / \mathrm{mol}$, and $M_{\mathrm{w}} / M_{\mathrm{n}}=2.01$.

DoD Piezo Inkjet Printing of the PFS 5-Based Ink. PFS 5 was dissolved in toluene at different concentrations, including $2.5,5$, and $10 \mathrm{wt} \%$; the corresponding solutions were named "ink A", "ink B", and "ink C", respectively. The physical and chemical properties of the inks are summarized in Table S1. The rheological properties and the surface tension of the inks were evaluated via steady-shear rate sweep and pendant drop measurements, respectively, as shown in the Supporting Information.

A Dimatix Piezo inkjet 2831 printer (FUJIFILM Dimatix Inc., Santa Clara, CA) PIXDRO LP 50, featuring a DMP-2850 print head and a DMC 11610 cartridge ( 16 nozzles having a $23 \mu \mathrm{m}$ diameter, 10 $\mathrm{pL}$ nominal drop volume), was used to deposit the redox-active ink on the MEAs. The droplet formation of the inks (i.e., the printability) was investigated by analyzing with the PIDRO Advanced Drop Analysis software (ADA, PixDro, Meyer Burger, The Netherlands) the drop generated in continuous inkjet printing mode. The alignment of the sample to the print head was obtained via the standard protocol employed from the PIDRO Advanced Drop Analysis software named "fiducial alignment". The alignment was performed on three reference points selected on the Au pad in the MEA chip, and it was considered optimal for score values above $90 \%$.

Synthesis Characterization of the Device: Surface and Electrochemical Properties. The surface and electrochemical properties of the PFS $\mathbf{5}$ printed MEA chips were studied by investigating the chemical composition of the printed films via energy dispersive X-ray EDX-HR SEM and mapping ATR-FTIR microscopy measurements and the topography and morphology via laser confocal microscopy and AFM. The electrical properties of the surfaceimmobilized PFS chains were studied by using cyclic voltammetry $(\mathrm{CV})$. More detailed information about the experimental part can be found in the Supporting Information.

\section{RESULTS AND DISCUSSION}

As mentioned in the Introduction, we present and discuss the design and the implementation of a potentially multiplexed electrochemical sensing device. The individual sensors in a fully multiplexed instrument can each hold different responsive materials for specific sensing applications, which need to be printed onto the micro electrode surface.

Synthesis of Disulfide-Functionalized Poly(ferrocenylsilane)s, PFS 5. First, we discuss the synthesis of a new PFS-based redox responsive polymer which can be immobilized via sulfur-gold coupling. This new PFS-based random copolymer was designed to possess a tailored number of disulfide moieties to ensure a stable covalent attachment of the polymer to the gold surface. Disulfide-modified poly(ferrocenylsilane) random copolymers were prepared in three 
Scheme 1. Synthesis of Disulfide-Functionalized PFS 5

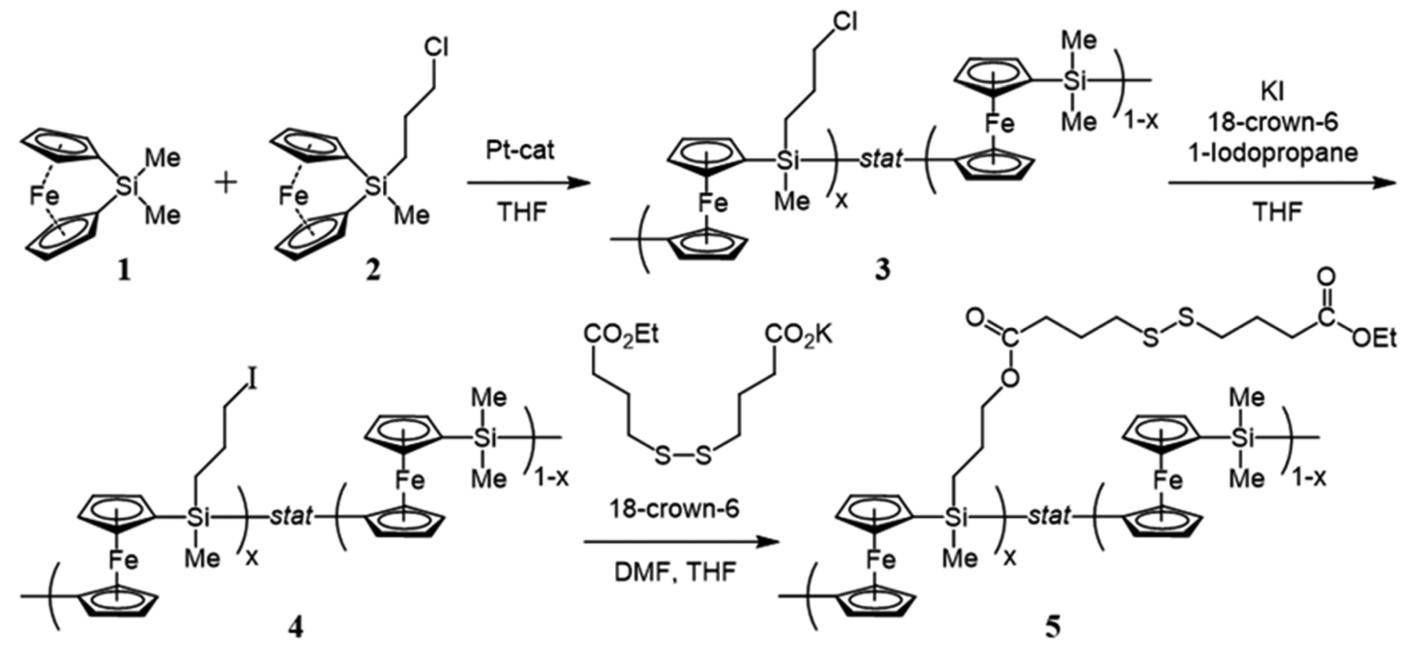

steps, starting with the transition-metal-catalyzed ring-opening polymerization (ROP) of [1]dimethylsilaferrocenophane 1 and [1](3-chloropropyl)methylsilaferrocenophane 2 to afford PFS 3 (Scheme 1).

The chloropropyl moieties introduced by copolymerization of $\mathbf{1}$ with ferrocenophane $\mathbf{2}$ enable further derivatization of the formed PFS chains by nucleophilic substitution, in this work by their conversion into more reactive iodopropyl groups, yielding PFS 4. Reaction of PFS 4 with the potassium salt of 4,4dithiobutyric acid monoethyl ester led to disulfide-functionalized PFS 5. As transition-metal-catalyzed random copolymerization of ferrocenophanes has been demonstrated earlier, we anticipated that the presence of $5 \mathrm{~mol} \%$ ferrocenophanes 2 in the monomer mixture would lead to the incorporation of a corresponding amount of disulfide groups along the PFS chains.

The PFS copolymers 3,4 , and 5 were characterized by ${ }^{1} \mathrm{H}$ and ${ }^{13} \mathrm{C}$ NMR spectroscopy, FTIR spectroscopy, and gel permeation chromatography (GPC) (see the Supporting Information). NMR spectroscopy confirmed the complete conversion of PFS 3 into its iodo analogue PFS 4 through halogen exchange (Figure S7). In addition, the attachment of the disulfide moieties to PFS 4 occurred with quantitative conversion. By comparing the integral of the characteristic $\mathrm{CH}_{2}-\mathrm{Cl}$ triplet at $\delta=3.24 \mathrm{ppm}$ with the integral of the ferrocene signals at $\delta=4.06$ and $4.24 \mathrm{ppm}$ of PFS 3, the chloropropyl group content was determined to be $\sim 7 \mathrm{~mol} \%$. A similar value was found for the amount of iodopropyl groups in the polymer 4 . The integrals of the signals belonging to the methylene moieties adjacent to the disulfide groups in polymer 5 at $\delta=2.45 \mathrm{ppm}$ showed a disulfide content of $5 \mathrm{~mol} \%$ in this polymer. In the FTIR spectrum of PFS 5, characteristic absorptions of the ester groups $(\mathrm{C}=\mathrm{O}$ stretch, 1750 and 1735 $\left.\mathrm{cm}^{-1}\right)$ and ferrocene rings $\left(1037,1182\right.$, and $\left.1165 \mathrm{~cm}^{-1}\right)$ were observed.

The molar masses of the macromolecules were determined by GPC measurements. For PFS 5, $M_{\mathrm{n}}=138500 \mathrm{~g} \mathrm{~mol}^{-1}, M_{\mathrm{w}}$ $=278800 \mathrm{~g} \mathrm{~mol}^{-1}$, and $M_{\mathrm{w}} / M_{\mathrm{n}}=2.0$ were found (the values refer to data determined using PS calibration standards). For this relatively high molar mass, with an average degree of polymerization $\mathrm{DP}_{\mathrm{n}}$ exceeding $500,5 \mathrm{~mol} \%$ corresponds to around 25 disulfide moieties per PFS chain, which should be sufficient for robust immobilization of these chains on gold surfaces in the sensing device.

DoD Piezo Inkjet Printing of the PFS 5-Based Ink. Following the completion of the synthesis of this new ink constituent PFS 5, our attention turned to the printing process and the printing accuracy. While this is obviously dependent on the printer device employed, some generic results will be discussed below. The first question to be tackled for a new ink is related to its printability.

Important physical properties regarding the ink encompass viscosity, density, and surface tension since these quantities affect the droplet formation and thus impact the repeatability and the accuracy of the inkjet deposition process. ${ }^{60,61,65,66}$ The requirements for a printable ink for the Pixdro LP50 inkjet printer equipped with a DMC-11610 cartridge, as used in this study, include a viscosity range between 1 and $20 \mathrm{mPa} \cdot \mathrm{s}$ and a surface tension between 25 and $50 \mathrm{mN} \mathrm{m}^{-1}$. Thus, regarding the formulation of the inks, the choice of the solvent is a key parameter, and it is necessary to consider the polymer solubility, the chemical stability over time, the surface tension, and the viscosity. In our case, toluene was a good candidate because it is a good solvent for PFS 5, with a low boiling temperature (allowing the ink to dry quickly enough to prevent smudging), and it also exhibits good wetting properties on gold.

As explained in more detail in the Experimental Section and in the Supporting Information, toluene-based inks with 2.5, 5, and 10 wt \% PFS 5, which are termed ink A, ink B, and ink C, respectively, were prepared, and their solution properties were characterized (Table S1). All solutions exhibited Newtonian behavior in the tested shear rate range between 500 and 2000 $\mathrm{s}^{-1}$. The shear viscosity values increased with an increasing solid content in the solution (between 1.8 and $11 \mathrm{mPa} \cdot \mathrm{s}$ ), and the surface tension values slightly decreased upon increasing the amount of polymer in the ink (between 28 and $26 \mathrm{mN}$ $\mathrm{m}^{-1}$ ), as shown in Figure S9. Consequently, all tested inks exhibited a suitable viscosity for inkjet printing, and their surface tension was compatible with the surface characteristics of the gold electrode surface.

We chose "ink A" as the best candidate in this work, as it provides good rheological properties (with shear viscosity of $1.8 \mathrm{mPa} \cdot \mathrm{s}$ ), ideal printability (i.e., stable, no satellite drops, repeatable droplet formation), accurate deposition, and a long 

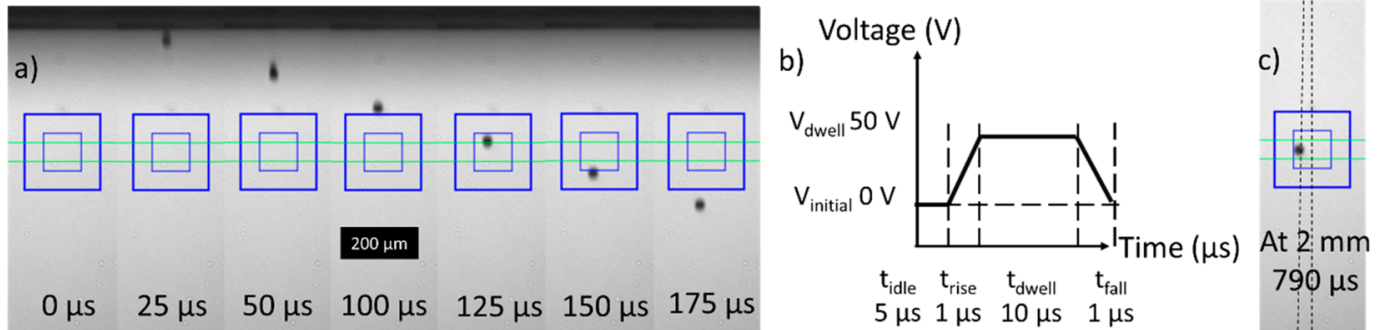

Figure 2. (a) Series of high-speed photographic images of "ink A" (see the Experimental Section) as it is ejected from the nozzle at times between 0 and $175 \mu \mathrm{s}$ after the start of the piezo actuation. Characteristics of the drop: speed $5 \mathrm{~m} \mathrm{~s}^{-1}$ and volume $10 \mathrm{pL}$. (b) The piezoelectric actuator waveform (potential vs time) used for a stable drop-on-demand inkjet printing of "ink A". (c) High-speed photographic image recorded at a distance of $2 \mathrm{~mm}$ from the nozzle which corresponds to the distance between the print head and the MAE substrate during the deposition of the ink, revealing a misalignment of $0.26^{\circ}$.

time storage stability (i.e., the physical and chemical ink properties were stable for more than 6 months). In addition, since it has the lowest concentration of PFS 5 required to obtain a printable ink, it also allows for the deposition of the lowest amount of PFS 5 per drop, eventually enhancing control over the deposited layer thickness. In fact, as shown in Figure $2 \mathrm{a}$ from the high-speed image collection, the ink developed a stable jet with drop volumes of about $10 \mathrm{pL}$ and a velocity of 5 $\mathrm{m} \mathrm{s}^{-1}$ by using the simple actuator waveform as depicted in Figure $2 \mathrm{~b}$. No satellite droplets formed during printing, and a good accuracy and precision with a misalignment of $<0.26^{\circ}$ were obtained, as shown in Figure 2c.

Characterization of the Device: Surface and Electrochemical Properties. The successful deposition of PFS 5 ink via inkjet printing was confirmed by visual inspection via optical and laser confocal microscopy. Then, the successful immobilization of the ultrathin redox-active polymer films onto the ME surface was verified via HR-SEM-EDX, ATR-FTIR microscopy, and cyclic voltammetry measurements, as shown in Figure 3 and in the Supporting Information. a)

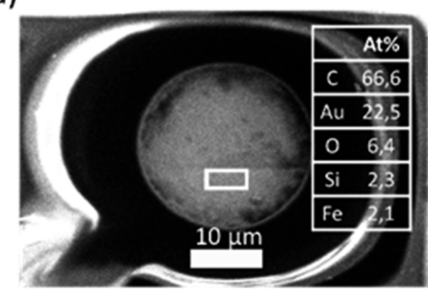

c)

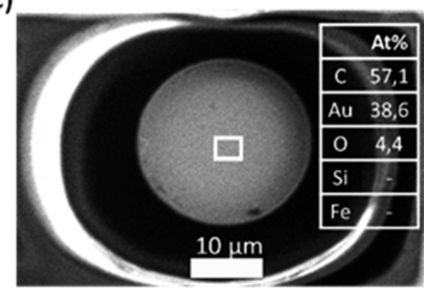

b)

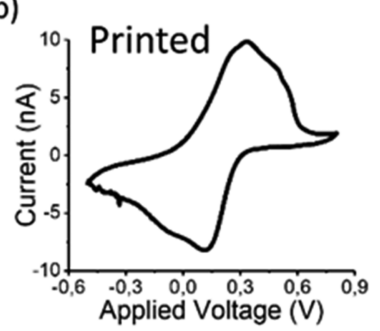

d)

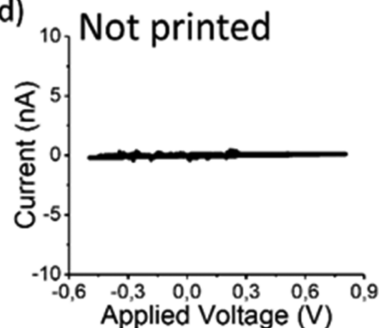

Figure 3. Surface characterization of the MEs via SEM-EDX: (a, c) SEM images of PFS 5-modified and bare gold electrodes of the MEA, respectively. The insets show the elemental composition of the areas in the rectangular white boxes. (b, d) CVs of a PFS 5-modified and a bare electrode of the MEA, respectively. Scan rate $50 \mathrm{mV} \mathrm{s}^{-1}$, in 100 $\mathrm{mM} \mathrm{NaClO}$, $\mathrm{Pt}$ (wire)-RE/CE, and potential range between -500 and $800 \mathrm{mV}$ vs Pt.
EDX analysis confirmed the presence of Fe and $\mathrm{Si}$ in equal atomic percentages after deposition of PFS 5 ink on the MEs, as is shown in the inset of the SEM images in Figure 3a,c. The presence of sulfur was not observed with EDX analysis since its concentration was below the sensitivity of the instrument. In FTIR spectra the typical absorbance bands of ferrocene and of the ester groups were detected, proving the grafting of the disulfide modified PFSs onto the gold surface, as shown in Figure S14. A morphological analysis of the PFS grafts was performed by AFM, confirming a generally flat and uniform topology over the electrode surfaces. AFM surface profile measurements showed that the value for the average step height of the dry PFS 5 film was $8 \pm 3 \mathrm{~nm}$ and the average surface roughness was $1.2 \pm 0.5 \mathrm{~nm}$, as shown in Figure $S 13$.

The conclusive confirmation of the successful ME surface modification was obtained by cyclic voltammetry (CV) measurements on the PFS 5-decorated MEs. As shown in Figures $3 \mathrm{~b}$ and $3 \mathrm{~d}$, the characteristic oxidation and reduction peaks of the ferrocene moieties of PFS (between -100 and $400 \mathrm{mV}$ vs Pt electrode) are clearly present for the printed electrodes, while no current was observed for the nonprinted MEs. The double-wave voltammogram, typical of PFS, indicates $\mathrm{p}-\pi \mathrm{d}-\pi$ electron orbital overlap due to electronic delocalization between neighboring ferrocene units in the polymer via the Si bridge. ${ }^{24,25,27,31}$ For some of the modified PFS 5 MEs, as shown in Figure S15, a single-wave voltammogram was recorded due to the (likely) instability of the positively charged intermediate in the aqueous solution, inhomogeneity of the coating, or different thickness of the polymer films and the resulting heterogeneity in electron transfer paths. 8,67

As shown in Figure S15, we propose a classification of the printing quality based on the electrochemical and electrocatalytic properties of the coated MEs differentiating among well-modified, poorly modified, and nonfunctionalized MEs. The electron transfer mechanism of the well-modified MEs was essentially reversible, while for the poorly modified electrodes the electron transfer process was more complex. Here the rate of electron transport through films and transport between the films and the electrode were rather slow (i.e., at low scan rates the process was quasi-reversible, while at high scan rates it was virtually irreversible). For the well-modified electrodes, the surface coverage, $\Gamma$, of PFS 5 was estimated, according to eq $1,{ }^{8}$ to be $1.6 \times 10^{-9} \mathrm{~mol}$ ferrocene units per $\mathrm{cm}^{2}$.

$$
\Gamma=Q /(n F A)
$$


in which $A$ is the geometric surface area of the gold working $\mathrm{ME}, n$ is the number of electrons involved in the redox process ( 1 for ferrocene units), $F$ is Faraday's constant $(96485 \mathrm{C} / \mathrm{mol}$ ), and $Q$ is the charge passed during the oxidation/reduction of ferrocene sites. The grafting value of $1.60 \times 10^{-9} \mathrm{~mol} \mathrm{~cm}^{-2}$ is on the order of magnitude of values shown in the literature for "grafted to" high molar mass macromolecules and indicates the presence of a thin, uniform, and relatively densely grafted PFS film on the electrode surface. ${ }^{8,20}$

To confirm the stability of deposited PFS $\mathbf{5}$ films on the ME, successive $\mathrm{CV}$ measurements were conducted. For comparison, repeated $\mathrm{CV}$ measurements were performed for deposited films of iodine-functionalized PFS (PFS 4). Figure 4 shows the CVs for PFS 5 (a) and PFS 4 (b) layers on gold electrodes.

a) PFS 5-mod. Au-ME

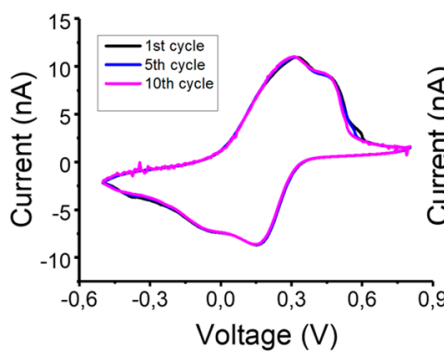

b) PFS 4-mod. Au-ME

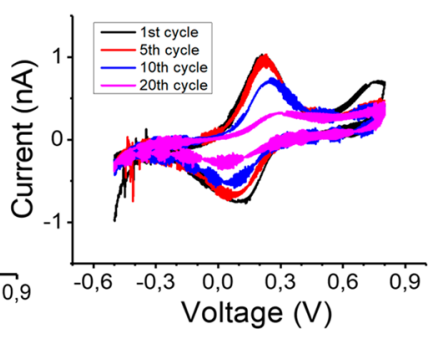

Figure 4. Evaluation of the electrochemical stability of printed surface-tethered PFS 5 layers printed on gold electrodes of the MEA by repeated CV measurements. Scan rate $50 \mathrm{mV} \mathrm{s}^{-1}$, in $100 \mathrm{mM}$ $\mathrm{NaClO}_{4}, \mathrm{Pt}$ (wire)-RE/CE, and potential range between -500 and $800 \mathrm{mV}$ vs Pt.

From Figure 4 it is clear that for PFS 5 films the oxidation and reduction peaks remained unchanged and are reproducible for more than 10 potential cycles, indicating that no PFS chains desorb from the substrate. On the other hand, as shown in Figure $4 b$, the oxidation and reduction currents for PFS 4 films decreased after each $\mathrm{CV}$, indicating the gradual desorption of the iodopropyl-functionalized PFS 4 from the $\mathrm{Au}-\mathrm{ME}$. Hence, the introduction of a disulfide functionality along the PFS backbone is a necessity to significantly enhance the printed layer stability on gold electrodes.

Having thus established the functionalization of an individual ME by inkjet printing, we then turned our attention to testing the individual microelectrode cells for sensing applications. For this purpose, we used ascorbic acid as a standard and well-characterized redox analyte. In earlier works, we have reported and described the use of PFS sensors for ascorbic acid detection. ${ }^{20,32-34}$ The PFS films used in these studies served as electron transfer mediator in the electrocatalytic oxidation of ascorbic acid in amperometric chemical sensors.

In Figure 5, we demonstrate the ability of the ME grafted PFS films to mediate and catalyze the electron transfer process of the ascorbic acid oxidation. Voltammograms for the bare and the modified gold MEs in presence and in the absence of ascorbic acid are shown.

The CVs of the PFS-immobilized Au-ME show a typical, essentially reversible redox response in the absence of the analyte (Figure 5a). In the presence of $35 \mathrm{mM}$ ascorbic acid, an enhanced anodic peak current (e.g., at $+0.4 \mathrm{~V}$ vs $\mathrm{Pt}$ ) was recorded, demonstrating the electrocatalytic properties of the PFS films. In the control experiment, the CVs of the bare MEs show a typical ascorbic acid oxidation redox wave (around $+0.37 \mathrm{~V} \mathrm{vs} \mathrm{Pt}$ ) without any enhancement of the anodic current, as shown in Figure $5 b$.

The amperometric response of a PFS-modified ME to the successive additions of ascorbic acid was evaluated through chronoamperometric measurements. These experiments allowed us to obtain information about the detection limit, DL, quantification limit, QL, sensitivity, linearity, and the limit of linearity (LOL) of the sensing pixel as shown in Figure 6.

The change in the anodic current increase upon adding ascorbic acid in the cell solution is described by the RandlesSevcik relationship ${ }^{8}$ (see Figure $6 \mathrm{~b}, \mathrm{c}$ ). The amperometric response of PFS-decorated MEs was rapid, and the anodic steady-state current was reached within a few seconds after the addition of an ascorbic acid aliquot. (We note that the registered spikes of the current were due to the manual injection of the analyte in the cell via a micropipette.) As shown in Figure 6d, calibration of the PFS modified electrode was performed, and it exhibited three regimes, ${ }^{68}$ i.e., the noise, a linear, and a nonlinear regime. The noise regime (up to 0.9 $\mathrm{mM}$ ) is characterized by an increase of the current as a function of the ascorbic acid concentration (coefficient of linear regression $\left.R^{2}=0.941\right)$, but with low sensitivity of the modified electrode (sensitivity is $9 \mathrm{nA} \mathrm{mM}^{-1}$, considering the slope of the linear regression) and low signal-to-noise ratio (below 100). Theoretically, the DL and the QL values can be defined as 3 and 10 times the standard deviation of the blank
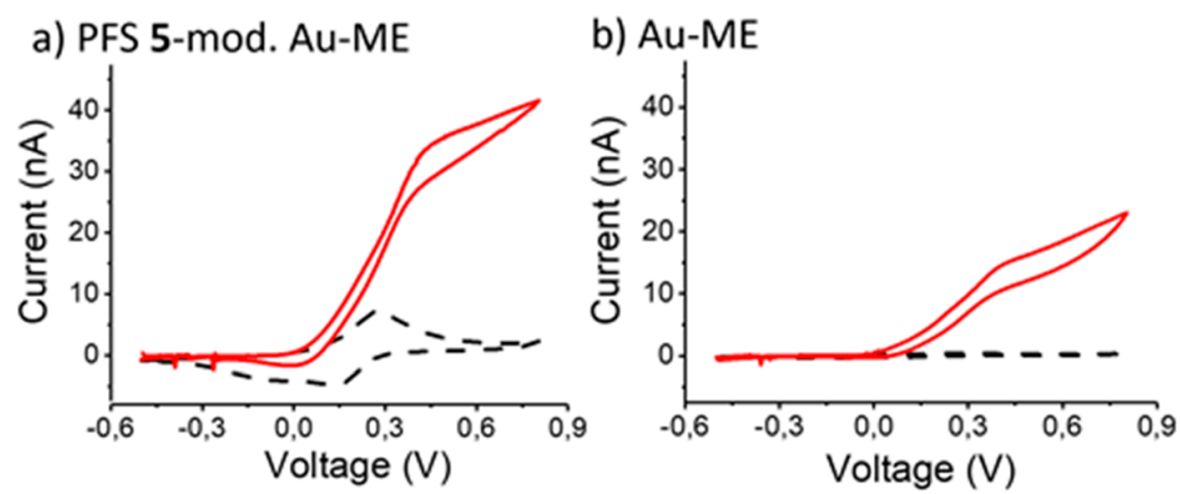

Figure 5. Comparison of CVs of the electrochemical properties in the presence (red solid line) and absence (black dashed line) of $35 \mathrm{mM}$ ascorbic acid for a PFS 5-modified (a) and unmodified (b) Au-MEs, respectively. Scan rate $50 \mathrm{mV} \mathrm{s}^{-1}$, in $100 \mathrm{mM} \mathrm{NaClO}_{4}, \mathrm{Pt}($ wire)-RE/CE, and potential range between -500 and $800 \mathrm{mV}$ vs Pt. 

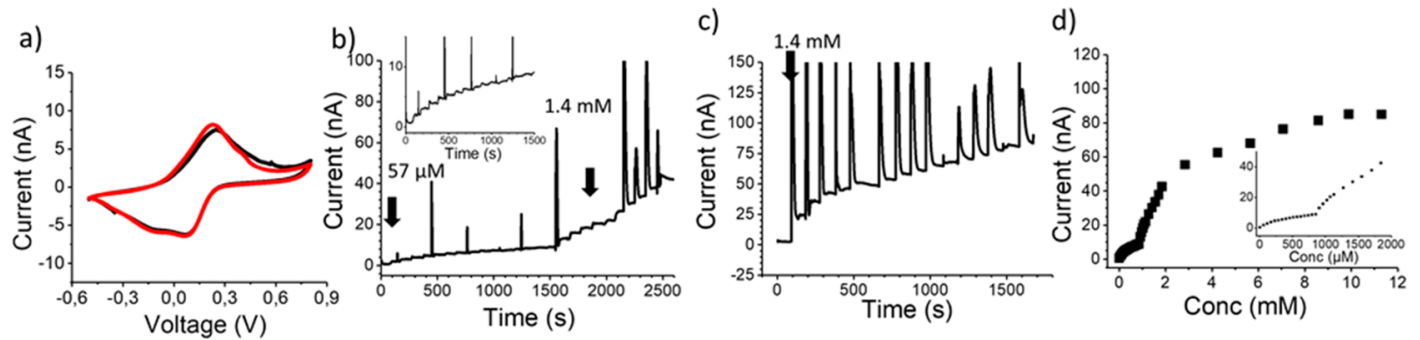

Figure 6. (a) Cyclic voltammogram of the PFS 5-modified ME used for the amperometric experiments before and after the amperometric experiments. Scan rate $50 \mathrm{mV} \mathrm{s}^{-1}$, in $100 \mathrm{mM} \mathrm{NaClO}$, Pt(wire)-RE/CE, and potential range between -500 and $800 \mathrm{mV}$ vs $\mathrm{Pt}$. Chronoamperometric response of a modified ME to the successive additions of ascorbic acid to evaluate (b) the limit of detection and (c) the linearity of the calibration curve. (d) Is the calibration process of a PFS 5-modified ME for ascorbic acid sensing. In the inset of d), the calibration curve between 0.057 and $2 \mathrm{mM}$ is shown. The cell contained $2 \mathrm{~mL}$ of $100 \mathrm{mM} \mathrm{NaClO}$ aqueous solution, $\mathrm{Pt}($ wire)-RE/CE, and the potential was set at $400 \mathrm{mV}$ vs Pt.

signal, respectively. Thus, the theoretical DL and the theoretical QL values were 33 and $111 \mu \mathrm{M}$, respectively, considering $0.1 \mathrm{nA}$ as the standard deviation of the anodic current value of the solution without the analyte. However, experimentally, the anodic current value increased with a welldefined step after the addition of $57 \mu \mathrm{M}$ of ascorbic acid in the cell solution, permitting us to define this concentration value as the experimental QL. The linear calibration regime, between 0.9 and $2 \mathrm{mM}$, is characterized by a linear increase of the current upon increasing the analyte concentration and a good sensitivity ( $\left.31.4 \mathrm{nA} \mathrm{mM}-1, R^{2}=0.985\right)$. In the nonlinear regime, above the LOL of $2 \mathrm{mM}$ ascorbic acid, a deviation from the linear regime was observed. This is caused by the slow diffusion rate of the analyte through the diffusion layer above the electroactive film with a drastic change in the sensitivity of the sensor (in the linear regime the sensitivity was $31.4 \mathrm{nA} \mathrm{mM}{ }^{-1}$, while in the nonlinear regime the sensitivity value dropped to $1.0 \mathrm{nA} \mathrm{mM}^{-1}$ ). The stability and the reproducibility of the electrochemical properties of the PFS modified MEs were tested before and after the amperometric experiments. As shown in Figure 6a, there were no changes in the CVs following the amperometric experiments. As such, the good stability of the printed PFS 5 layers was confirmed once more, demonstrating their feasibility to be utilized as inks that allow advancement to the required next step, which is the development of MEAs with analyte-specific readouts for its individual MEs.

\section{CONCLUSIONS}

New redox-responsive polymers, i.e., PFS 5, with a PFS backbone and $5 \mathrm{~mol} \%$ side groups with disulfide units were successfully synthesized and exploited as molecular inks for the spatially controlled surface modification of commercial MEAs by drop-on-demand (DOD) inkjet printing. First, PFS $\mathbf{5}$ inks in toluene with a viscosity and surface tension of $1.8 \mathrm{mPa} \cdot \mathrm{s}$ and $28 \mathrm{mN} \mathrm{m}^{-1}$ as determined by rheology and pendant drop measurements were developed. Subsequently, commercial MEAs were modified using PFS 5-based ink by printing in DoD mode with good accuracy. FTIR spectroscopy and EDXSEM confirmed a successful, spatially localized PFS surface modification of the individual gold-coated MEs. The deposited PFS 5 layer thickness was $\sim 8 \mathrm{~nm}$ as was estimated from AFM analysis, while from $\mathrm{CV}$ measurements a ferrocene unit grafting density of $1.60 \times 10^{-9} \mathrm{~mol} \mathrm{~cm}{ }^{-2}$ was determined, confirming the presence of an ultrathin, uniform, and relative densely grafted PFS film on the electrode surface. Repeated CV measurements confirmed the redox activity and stability of the printed PFS layers on the modified MEAs. The good layer stability was ascribed to the strong and stable bonding between the gold electrode surface and the PFS disulfide side groups. Finally, the potential of these devices to act as an electrochemical sensor array was demonstrated with a model analyte, ascorbic acid, by using cyclic voltammetry and amperometric measurements. Good sensitivity and stable responses to ascorbic acid were achieved. To conclude, the first steps toward the multiplex "pixel-based" electrochemical sensing by DoD-IJ PFS modified MEAs were successfully demonstrated. Future efforts should be directed toward the development of printed analyte specific microelectrode array "pixels".

\section{ASSOCIATED CONTENT}

\section{S Supporting Information}

The Supporting Information is available free of charge on the ACS Publications website at DOI: 10.1021/acsami.9b11927.

Synthesis and characterization of the PFS copolymers, formulation and characterization of the ink, inkjet printing, and characterization of the printed MEAs (PDF)

\section{AUTHOR INFORMATION}

\section{Corresponding Author}

*E-mail: g.j.vancso@utwente.nl.

ORCID

Marco Cirelli: 0000-0001-7176-0566

Joost Duvigneau: 0000-0002-2810-2768

G. Julius Vancso: 0000-0003-4718-0507

\section{Notes}

The authors declare no competing financial interest.

\section{ACKNOWLEDGMENTS}

M.C., T.C.B., R.A., and G.J.V. thank the Marie Curie initial training network "Complex Wetting Phenomena" (CoWet), grant agreement 607861. N.B. acknowledges funding from DruIDe and Interreg $\mathrm{V}$ projects. Support by the MESA+ Institute for Nanotechnology of the University of Twente is also acknowledged.

\section{ABBREVIATIONS}

PFS, poly(ferrocenylsilane); MEA, microelectrode array; IJ, inkjet; DoD, drop-on-demand; C-IJ, continuous inkjet printing; FTIR, Fourier transform infrared; AFM, atomic force microscopy; $\mathrm{CV}$, cyclic voltammetry; $\mathrm{ME}$, modified 
electrode; RE, reference electrode; CE, counter electrode; DL, detection limit; QL, quantification limit; LOL, limit of linearity.

\section{REFERENCES}

(1) Thomas, C., Jr.; Springer, P. A.; Loeb, G. E.; Berwald-Netter, Y.; Okun, L. M. A Miniature Microelectrode Array to Monitor the Bioelectric Activity of Cultured Cells. Exp. Cell Res. 1972, 74 (1), 6166.

(2) Feeney, R.; Kounaves, S. P. Microfabricated Ultramicroelectrode Arrays: Developments, Advances, and Applications in Environmental Analysis. Electroanalysis 2000, 12 (9), 677-684.

(3) Pine, J. A History of MEA Development. In Advances in Network Electrophysiology; Springer: 2006; pp 3-23.

(4) Spira, M. E.; Hai, A. Multi-Electrode Array Technologies for Neuroscience and Cardiology. Nat. Nanotechnol. 2013, 8 (2), 83-94.

(5) Obien, M. E. J.; Deligkaris, K.; Bullmann, T.; Bakkum, D. J.; Frey, U. Revealing Neuronal Function through Microelectrode Array Recordings. Front. Neurosci. 2015, 8 (423), 1-30.

(6) Nagale, M. P.; Fritsch, I. Individually Addressable, Submicrometer Band Electrode Arrays. 1. Fabrication from Multilayered Materials. Anal. Chem. 1998, 70 (14), 2902-2907.

(7) Nagale, M. P.; Fritsch, I. Individually Addressable, Submicrometer Band Electrode Arrays. 2. Electrochemical Characterization. Anal. Chem. 1998, 70 (14), 2908-2913.

(8) Bard, A. J.; Faulkner, L. R. Fundamentals and Applications. Electrochem. Methods 2001, 2 (482), 580-632.

(9) Escuder-Gilabert, L.; Peris, M. Highlights in Recent Applications of Electronic Tongues in Food Analysis. Anal. Chim. Acta 2010, 665 (1), 15-25.

(10) Dimaki, M.; Vergani, M.; Heiskanen, A.; Kwasny, D.; Sasso, L.; Carminati, M.; Gerrard, J.; Emneus, J.; Svendsen, W. A Compact Microelectrode Array Chip with Multiple Measuring Sites for Electrochemical Applications. Sensors 2014, 14 (6), 9505-9521.

(11) Mendes, P. M. Stimuli-Responsive Surfaces for BioApplications. Chem. Soc. Rev. 2008, 37 (11), 2512-2529.

(12) Bawa, P.; Pillay, V.; Choonara, Y. E.; Du Toit, L. C. StimuliResponsive Polymers and their Applications in Drug Delivery. Biomed. Mater. 2009, 4 (2), 022001.

(13) Roy, D.; Cambre, J. N.; Sumerlin, B. S. Future Perspectives and Recent Advances in Stimuli-Responsive Materials. Prog. Polym. Sci. 2010, 35 (12), 278-301.

(14) Stuart, M. A. C.; Huck, W. T. S.; Genzer, J.; Muller, M.; Ober, C.; Stamm, M.; Sukhorukov, G. B.; Szleifer, I.; Tsukruk, V. V.; Urban, M.; Winnik, F.; Zauscher, S.; Luzinov, I.; Minko, S. Emerging Applications of Stimuli-Responsive Polymer Materials. Nat. Mater. 2010, 9 (2), 101-113.

(15) Schattling, P.; Jochum, F. D.; Theato, P. Multi-Stimuli Responsive Polymers-The All-In-One Talents. Polym. Chem. 2014, 5 (1), 25-36.

(16) Xie, G.; Khabibullin, A.; Pietrasik, J.; Yan, J.; Matyjaszewski, K. Polymer Brushes by Atom Transfer Radical Polymerization. Polymer and Biopolymer Brushes: For Materials Science and Biotechnology 2017, 2 (242), 29-97.

(17) Whittell, G. R.; Manners, I. Metallopolymers: New Multifunctional Materials. Adv. Mater. 2007, 19 (21), 3439-3468.

(18) Song, J.; Vancso, G. J. Responsive Organometallic Polymer Grafts: Electrochemical Switching of Surface Properties and Current Mediation Behavior. Langmuir 2011, 27 (11), 6822-6829.

(19) Nakahata, M.; Takashima, Y.; Yamaguchi, H.; Harada, A. Redox-Responsive Self-Healing Materials Formed from Host-Guest Polymers. Nat. Commun. 2011, 2 (1), 1-6.

(20) Sui, X.; Feng, X.; Song, J.; Hempenius, M. A.; Vancso, G. J. Electrochemical Sensing by Surface-Immobilized Poly(ferrocenylsilane) Grafts. J. Mater. Chem. 2012, 22 (22), 1126111267.
(21) Feng, X.; Zhang, K.; Hempenius, M. A.; Vancso, G. J. Organometallic Polymers for Electrode Decoration in Sensing Applications. RSC Adv. 2015, 5 (129), 106355-106376.

(22) Nguyen, P.; Gómez-Elipe, P.; Manners, I. Organometallic Polymers with Transition Metals in the Main Chain. Chem. Rev. 1999, 99 (6), 1515-1548.

(23) Giannotti, M.; Lv, H.; Ma, Y.; Steenvoorden, M.; Overweg, A.; Roerdink, M.; Hempenius, M. A.; Vancso, G. J. Stimulus Responsive Poly(ferrocenylsilanes): Redox Chemistry of Iron in the Main Chain. J. Inorg. Organomet. Polym. Mater. 2005, 15 (4), 527-540.

(24) Hailes, R. L.; Oliver, A. M.; Gwyther, J.; Whittell, G. R.; Manners, I. PolyFerrocenylSilanes: Synthesis, Properties, and Applications. Chem. Soc. Rev. 2016, 45 (19), 5358-5407.

(25) Foucher, D.; Ziembinski, R.; Petersen, R.; Pudelski, J.; Edwards, M.; Ni, Y.; Massey, J.; Jaeger, C. R.; Vancso, G. J.; Manners, I. Synthesis, Characterization, and Properties of High Molecular Weight Unsymmetrically Substituted Poly(ferrocenylsilanes). Macromolecules 1994, 27 (14), 3992-3999.

(26) Zou, S.; Ma, Y.; Hempenius, M. A.; Schönherr, H.; Vancso, G. J. Grafting of Single, Stimuli-Responsive Poly(ferrocenylsilane) Polymer Chains to Gold Surfaces. Langmuir 2004, 20 (15), 62786287.

(27) Nguyen, M. T.; Diaz, A. F.; Dement'ev, V. V.; Pannell, K. H. Electrochemical and Electrochromic Properties of Poly(dialkylsilyleneferrocenylene) Films. Chem. Mater. 1994, 6 (7), 952-954.

(28) Rulkens, R.; Ni, Y.; Manners, I. Living Anionic Ring-Opening Polymerization of Silicon-Bridged [1]Ferrocenophanes: Synthesis and Characterization of Poly(ferrocenylsilane)-Polysiloxane Block Copolymers. J. Am. Chem. Soc. 1994, 116 (26), 12121-12122.

(29) Péter, M.; Lammertink, R. G.; Hempenius, M. A.; Vancso, G. J. Electrochemistry of Surface-Grafted Stimulus-Responsive Monolayers of Poly(ferrocenyldimethylsilane) on Gold. Langmuir 2005, 21 (11), $5115-5123$.

(30) Foucher, D. A.; Honeyman, C. H.; Nelson, J. M.; Tang, B. Z.; Manners, I. Organometallic Ferrocenyl Polymers Displaying Tunable Cooperative Interactions Between Transition Metal Centers. Angew. Chem., Int. Ed. Engl. 1993, 32 (12), 1709-1711.

(31) Rulkens, R.; Lough, A. J.; Manners, I.; Lovelace, S. R.; Grant, C.; Geiger, W. E. Linear Oligo (ferrocenyldimethylsilane) with Between Two and Nine Ferrocene Units: Electrochemical and Structural Models for Poly(ferrocenylsilane) High Polymers. J. Am. Chem. Soc. 1996, 118 (50), 12683-12695.

(32) Cui, K.; Song, Y.; Wang, L. Electrochemical and Electrocatalytic Behaviors of Poly(ferrocenylsilane)/DNA Modified Glass Carbon Electrode. Electrochem. Commun. 2008, 10 (11), 1712-1715.

(33) Feng, X.; Sui, X.; Hempenius, M. A.; Vancso, G. J. Electrografting of Stimuli-Responsive, Redox Active Organometallic Polymers to Gold from Ionic Liquids. J. Am. Chem. Soc. 2014, 136 (22), 7865-7868.

(34) Feng, X.; Cumurcu, A.; Sui, X.; Song, J.; Hempenius, M. A.; Vancso, G. J. Covalent Layer-by-Layer Assembly of Redox-Active Polymer Multilayers. Langmuir 2013, 29 (24), 7257-7265.

(35) Hendry, S.; Cardosi, M.; Turner, A.; Neuse, E. Polyferrocenes as Mediators in Amperometric Biosensors for Glucose. Anal. Chim. Acta 1993, 281 (3), 453-459.

(36) Lee, J.; Ahn, H.; Choi, I.; Boese, M.; Park, M. J. Enhanced Charge Transport in Enzyme-Wired Organometallic Block Copolymers for Bioenergy and Biosensors. Macromolecules 2012, 45 (7), $3121-3128$

(37) Chen, C.; Song, Y.; Wang, L. A Novel Sensor Based on Layer by Layer Hybridized Phosphomolybdate and Poly(ferrocenylsilane) on a Cysteamine Modified Gold Electrode. Electroanalysis 2008, 20 (23), 2543-2548.

(38) Cyr, P. W.; Tzolov, M.; Manners, I.; Sargent, E. H. Photooxidation and Photoconductivity of Poly(ferrocenylsilane) Thin Films. Macromol. Chem. Phys. 2003, 204 (7), 915-921.

(39) Xu, Z.; Dong, Q.; Otieno, B.; Liu, Y.; Williams, I.; Cai, D.; Li, Y.; Lei, Y.; Li, B. Real-Time In Situ Sensing of Multiple Water Quality 
Related Parameters using Micro-Electrode Array (MEA) Fabricated by Inkjet-Printing Technology (IPT). Sens. Actuators, B 2016, 237, $1108-1119$

(40) Rapini, R.; Marrazza, G. Electrochemical Aptasensors for Contaminants Detection in Food and Environment: Recent Advances. Bioelectrochemistry 2017, 118, 47-61.

(41) Huang, X. J.; O’Mahony, A. M.; Compton, R. G. Microelectrode Arrays for Electrochemistry: Approaches to Fabrication. Small 2009, 5 (7), 776-788.

(42) Wang, J. Modified Electrodes for Electrochemical Sensors. Electroanalysis 1991, 3 (4-5), 255-259.

(43) Falconnet, D.; Csucs, G.; Grandin, H. M.; Textor, M. Surface Engineering Approaches to Micropattern Surfaces for Cell-Based Assays. Biomaterials 2006, 27 (16), 3044-3063.

(44) Adly, N.; Weidlich, S.; Seyock, S.; Brings, F.; Yakushenko, A.; Offenhäusser, A.; Wolfrum, B. Printed Microelectrode Arrays on Soft Materials: from PDMS to Hydrogels. npj Flex. Electron. 2018, 2 (1), $1-15$.

(45) Edmondson, S.; Osborne, V. L.; Huck, W. T. Polymer Brushes via Surface-Initiated Polymerizations. Chem. Soc. Rev. 2004, 33 (1), $14-22$.

(46) Barbey, R.; Lavanant, L.; Paripovic, D.; Schuwer, N.; Sugnaux, C.; Tugulu, S.; Klok, H.-A. Polymer Brushes via Surface-Initiated Controlled Radical Polymerization: Synthesis, Characterization, Properties, and Applications. Chem. Rev. 2009, 109 (11), 5437-5527.

(47) Zoppe, J. O.; Ataman, N. C.; Mocny, P.; Wang, J.; Moraes, J.; Klok, H.-A. Surface-Initiated Controlled Radical Polymerization: State-of-the-Art, Opportunities, and Challenges in Surface and Interface Engineering with Polymer Brushes. Chem. Rev. 2017, 117 (3), 1105-1318.

(48) Zdyrko, B.; Luzinov, I. Polymer Brushes by the "Grafting To" Method. Macromol. Rapid Commun. 2011, 32 (12), 859-869.

(49) Love, J. C.; Estroff, L. A.; Kriebel, J. K.; Nuzzo, R. G.; Whitesides, G. M. Self-Assembled Monolayers of Thiolates on Metals as a Form of Nanotechnology. Chem. Rev. 2005, 105 (4), 1103-1170.

(50) Pensa, E.; Cortes, E.; Corthey, G.; Carro, P.; Vericat, C.; Fonticelli, M. H.; Benitez, G.; Rubert, A. A.; Salvarezza, R. C. The Chemistry of the Sulfur-Gold Interface: in Search of a Unified Model. Acc. Chem. Res. 2012, 45 (8), 1183-1192.

(51) Péter, M.; Lammertink, R. G. H.; Hempenius, M. A.; Julius Vancso, G.; van Os, M.; Knoll, W.; Beulen, M. W. J.; Reinhoudt, D. N. Synthesis, Characterization and Thin Film Formation of EndFunctionalized Organometallic Polymers. Chem. Commun. 1999, No. 4, 359-360.

(52) Chabanne, L.; Pfirrmann, S.; Lunn, D. J.; Manners, I. Controlled Thiol-Ene Post-Polymerization Reactions on Poly(ferrocenylsilane) Homopolymers and Block Copolymers. Polym. Chem. 2013, 4 (7), 2353-2360.

(53) Gómez Elipe, P.; Macdonald, P. M.; Manners, I. Architectural Control in the Transition Metal Catalyzed Ring Opening Polymerization of Silicon Bridged [1] Ferrocenophanes. Angew. Chem., Int. Ed. Engl. 1997, 36 (7), 762-764.

(54) Hempenius, M. A.; Brito, F. F.; Vancso, G. J. Synthesis and Characterization of Anionic and Cationic Poly(ferrocenylsilane) Polyelectrolytes. Macromolecules 2003, 36 (17), 6683-6688.

(55) Song, J.; Jańczewski, D.; Ma, Y.; van Ingen, L.; Ee Sim, C.; Goh, Q.; Xu, J.; Vancso, G. J. Electrochemically Controlled Release of Molecular Guests from Redox Responsive Polymeric Multilayers and Devices. Eur. Polym. J. 2013, 49 (9), 2477-2484.

(56) Lammertink, R. G.; Hempenius, M. A.; Vancso, G. J.; Shin, K.; Rafailovich, M. H.; Sokolov, J. Morphology and Surface Relief Structures of Asymmetric Poly (styrene-block-ferrocenylsilane) Thin Films. Macromolecules 2001, 34 (4), 942-950.

(57) Calvert, P. P. P. Inkjet Printing for Materials and Devices. Chem. Mater. 2001, 13 (10), 3299-3305.

(58) De Gans, B. J.; Duineveld, P. C.; Schubert, U. S. Inkjet Printing of Polymers: State of the Art and Future Developments. Adv. Mater. 2004, 16 (3), 203-213.
(59) Geissler, M.; Xia, Y. Patterning: Principles and Some New Developments. Adv. Mater. 2004, 16 (15), 1249-1269.

(60) Li, J.; Rossignol, F.; Macdonald, J. Inkjet Printing for Biosensor Fabrication: Combining Chemistry and Technology for Advanced Manufacturing. Lab Chip 2015, 15 (12), 2538-2558.

(61) Moya, A.; Gabriel, G.; Villa, R.; del Campo, F. J. Inkjet-Printed Electrochemical Sensors. Curr. Opin. Electrochem. 2017, 3 (1), 29-39.

(62) Derby, B. Inkjet Printing of Functional and Structural Materials: Fluid Property Requirements, Feature Stability, and Resolution. Annu. Rev. Mater. Res. 2010, 40, 395-414.

(63) Hoath, S. D. Fundamentals of Inkjet Printing: The Science of Inkjet and Droplets; John Wiley \& Sons: 2016.

(64) Avila-Zárraga, J. G.; Martínez, R. Efficient Methylation of Carboxylic Acids with Potassium Hydroxide/Methyl Sulfoxide and Iodomethane. Synth. Commun. 2001, 31 (14), 2177-2183.

(65) Wijshoff, H. The Dynamics of the Piezo Inkjet Printhead Operation. Phys. Rep. 2010, 491 (4), 77-177.

(66) Komuro, N.; Takaki, S.; Suzuki, K.; Citterio, D. Inkjet Printed

(Bio) Chemical Sensing Devices. Anal. Bioanal. Chem. 2013, 405 (17), 5785-5805.

(67) Evans, D. H. One-Electron and Two-Electron Transfers in Electrochemistry and Homogeneous Solution Reactions. Chem. Rev. 2008, 108 (7), 2113-2144.

(68) O'Hare, D. Biosensors and Sensor Systems. In Body Sensor Networks; Springer: 2014; pp 55-115. 